\title{
Current Situation and Results on English Translation Research for Chinese Cultural Classics
}

\author{
Fenghua Li \\ Teaching and Research Institute of Foreign Languages, Bohai University, Jinzhou, 121013, China \\ Izy8917891@163.com
}

Keywords: Chinese cultural classics; English translation; current situation and results; conveying the spirit and meaning; faithfulness, expressiveness and elegance

\begin{abstract}
Chinese classics is bearing the weight of the history and culture of messiness, books in English translation is the main channel of Chinese excellent traditional culture to the world. In-depth analysis of the literature has been taken to the domestic and foreign numerous in this article, combing Chinese cultural classics works the current situation and results of the English translation. The research content mainly includes three aspects, the achievements and the existing problems of Chinese literature in English translation;"conveying the spirit and meaning" of the research and application, and points out the main points of the "conveying the spirit and meaning"; "Faithfulness, expressiveness and elegance" standard of inherit and development, and points out the core content of "faithfulness, expressiveness and elegance". This paper research the successful use of cost, plays an important role in such aspects of studying and formulating translation strategy, select material and translation theory.
\end{abstract}

\section{Introduction}

Five thousand-year history of the Chinese nation is carrying Chinese civilization great contributions to world civilization. Huaxia civilization and Chinese culture has a long history, extensive and profound. The Chinese classics in Chinese characters to save and come down, voluminous, has attracted worldwide attention. It is the spiritual wealth of mankind. However, from the late qing dynasty to a time long before the reform and opening up, China's door has been closed, not only blocked the path to learn from foreign, also hindered China to spread outside their own cultural classics. Since China's reform and opening up, Chinese economy fast development, to enhance the comprehensive national strength, improve the international status, many countries began to look to China [1]. Policies and development strategies of the Chinese government in such aspects as politics, economy, military and diplomatic embody the traditional Chinese culture and philosophy. Many countries realized that to understand China, you must understand Chinese culture for thousands of years old. In this background, the Chinese classics translation arises at the historic moment. Chinese classics translation refers to translating Chinese classics into English, using English to Chinese classics of accurate and complete representation of a kind of language activity. Classics translation plays an important role in foreign publicity the Chinese culture, promote world cultural exchanges. Under the background of globalization, however, translation of Chinese ancient book is also facing many problems, such as quality of translators, translation strategies. In recent years, the ancient book translation cause in China presents the good development momentum. Translation studies as an interdisciplinary field of study attract more and more attention from scholars. Many classics master made many contributions in this aspect, more and more experts and scholars also translation texts of the theory and method were studied. This article through to the domestic and foreign numerous in-depth analysis of the literature, combing the Chinese culture of the works, the present situation and results of the English translation, in order to better serve the Chinese culture in Chinese classics translation strategy to go out.

\section{Achieved Results and Existing Problems}

Chinese literature work in English translation studies mainly from a theoretical perspective, analysis 
of a translation, research on the phenomenon of a specific translation work, as well as a comparative study of multiple translation work [2]. It is gratifying achievements, and a lot of problems, summarized as follows:

Achievements [3,4]. Chinese classics translation studies the characteristics of the obvious, both to the traditional view of digging, and international vision, the achievements mainly in the following aspects: academic combined with universality. Generalized including linguistics, classics translation characteristics and principles, subject and object game and spread abroad, etc., put forward the methodology of related system. Academic mainly around issues of China's cultural classics translation theory. It has carried on the deep discussion and published a number of new ideas. Classics of the breadth and depth in the study of the translation constantly move forward, and rose to the height of the national cultural strategy. Booming national classics translation and research. Only the nation is the world. Ethnic development and prosperity of cultural undertakings, and promote the minority cultures of foreign communication, is the historical mission of national classics translation. National classics translation has been a breakthrough and achievement, which to strengthen national classics translation and promote harmonious ethnic relations is of great significance. At the same time, it brings help to promote the national culture of the mining, sorting and protection, to build complete "Chinese learning", to communication and transportation of all nationalities, and also other countries to complete understanding of Chinese culture and national characteristics. Continue to further traditional classics translation and research. Chinese traditional classics mainly refers to thought books, literature books and other books. Literature classics has always been the research focus. Second is thought class, and other class books are less. Literature classics research focus mainly concentrated in the fiction and poetry. Literary classics translation in the process of research to develop the vision, change the way of thinking. In literary theory and poetics theory, literary history and evaluation to find new resources, and then make the literary classics translation and research on a new look. Chinese ancient book evaluation research has already begun. With China's national strength increasing and Chinese culture to go out, the Chinese ancient book evaluation research agenda step by step. The next step of the main job is to collect data, draw lessons from Chinese and foreign history theory, literary theory, and the theory of translation, to write with theoretical height and level of Chinese translation history books. The study for the Chinese classics translation practice and translation theory and translation criticism, even for Chinese and foreign history, Chinese culture, Chinese civilization and cultural dissemination strategy, which has immeasurable value.

Existing problems [5,6]. Translation of Chinese classics career has considerable amount of translation and research projects. It has made remarkable achievements, also faces many problems, mainly displays in: the material is more onefold, mostly concentrated in the classical literary works, and some even have multiple versions, but its many literary classics and minority characters in ancient books have not been translated. The disconnection between theory and practice, the majority of English translation of Chinese classics practitioners do not engage in theoretical research, theoretical researchers basically do not engage in translation practice. Due to the traditional understanding, or affected by modern ideology, academic thought and historical understanding produce deviation. Lack of external communication channels, the English translation of Chinese classics world full of to the world the desire, and hosted by the Chinese translator English translation of Chinese classics works in overseas publication and influence is far from satisfactory. The lack of Chinese civilization history of comprehensive understanding and the profound understanding. Material is not good. Evaluation is not objective. Translation talents needs to be enriched, the majority in the senior experts in English translation of Chinese classics is getting into the old and middle-aged people and serious lack, the fault phenomena of English translation of Chinese Classics translators teams appear. Exchanges and cooperation need to be strengthened, overseas the translator's translation of the main issue in the overseas, the translator's translation is mainly distributed in the domestic so that the lack of communication each other. There is misunderstanding on the translation of Chinese classics into English, the translation of Chinese classics into English translation of the feasibility of the existence of misunderstanding, the 
translation theory and practice and the relationship between the domestic and foreign knowledge, the translation of the translation criteria, the translation of academic standards, translation of professional personnel training, translation teaching and other basic and institutional work and so on.

\section{Research and Application of "Conveying the Spirit and Meaning" Thought}

In the conveying the spirit and meaning of "book of songs", the foreign language school of Soochow University Wang Rongpei professor in Chinese translation scholars put forward "conveying the spirit and meaning" for the first time. He cited the "modern Chinese Dictionary" in the definition of "conveying the spirit" are discussed. Conveying the spirit should give people a vivid impression, this is the difference between translation and creation[7,8].conveying the spirit more important is the spirit, also is in essence similar, is to convey the original look, including form, tone of voice, image and rhetoric. To "expressive" as the premise, but different in word to word, sentence for sentence corresponding spirit must be, but in the spiritual essence of the corresponding or similar, so as to give people a vivid impression. "express the meaning" the meaning of the original, especially the deep meaning, but also try to take care of the surface meaning. "Meaning" can be divided into words "meaning" and "meaning of metaphor". "Meaning" is the expression of ideas, words, sentences, etc. chapter all levels are "expressive" problems. "The rational use of metaphor meaning" that figures of speech, but also played an important role. conveying the spirit and "expressive" and not a parallel structure, the "expressive" is the starting point of translation, conveying the spirit is the adverbial of "expressive" and conveying the spirit to "expressive". It can be seen that the translator can accurately express the meaning of the original meaning of this is the most basic requirements, but also the most important. The second is to convey the original expression, which is to play the role of icing on the cake. conveying the spirit includes not only the transfer of external form, including the transfer of inner meaning.

Translation is a process of text conversion, the conversion is "expressive", on the basis of "expressive" do conveying the spirit into a higher level, also can say, from the "expressive" to conveying the spirit can be regarded as a translation from the low level to the high level of the development process. "Expressive" is the intrinsic thing, is hiding behind the text of the meaning, and conveying the spirit is able to feel content, the content of external. This requires the further theoretical provisions conveying the spirit."Expressive" is the goal, is the minimum requirement of translation; conveying the spirit is the translation from the linguistic form, conveying the spirit is the relationship between form and content, the two are inseparable entity. Only the "expressive" no conveying the spirit, it will cause the translation of jerky, readers do not love to read; if only conveying the spirit not "to express", it will cause lack of translation "faithfulness". Therefore, conveying the spirit and "expressive" not at both ends of the points, not from the "expressive" to conveying the spirit, but the relationship between content and form, both in translation can not be separated, the combination can form an organic unity, pointing out the direction for translation[9].

The point is shown in Fig. 1 of "conveying the spirit and meaning". "Meaning" is the essence of translation. Translation begins with understanding, and finally expresses. In order to realize the diction of "meaning", on the understanding of "meaning" and "Dayi thought". It is summarized as three main points, semantic level, pragmatic level and cognitive level [10].First is semantic level. That is, the specific language of the specific symbol of the content, is the most direct translation of the object, but also the starting point of translation. Second is pragmatic level. Namely, the content of the original text and the actual content of the author's expression are different, so that the real content of the author's expression should be understood in translation. Refers to the cognitive subject's cognitive activities, along with the gradual deepening of understanding of the original text, mining to express the cultural content. From the semantic level to the pragmatic level to the cognitive level, the presentation is an abstract situation gradually, the translator has experienced such a gradual abstraction process of change."Conveying the spirit" is the soul of translation, answer the questions the translator in the translation process "God", mainly including five points, literary, style, mood, emotion and form. First is genre. The genre is a literary genre, that is, the 
specific style of literary works and different styles has different expression of styles. Refers to the writer's creative personality in the specific work of the performance, is a writer to distinguish the distinct personality. Third is artistic conception. It is an important category of Chinese classical aesthetics, and it is the general regularity of the creation of ancient Chinese literary works. Fourth is emotion. Literary works are full of writers' rich emotion, the author is infected with his own emotion; fifth, form. Literary works have a specific form, to be concise and rigorous, will not produce loose or bloated. The "literary, style, mood, emotion and form" as conveying the spirit points is completely out of the understanding of classical works clear. These dominant points has the relative stability, rationality and feasibility.

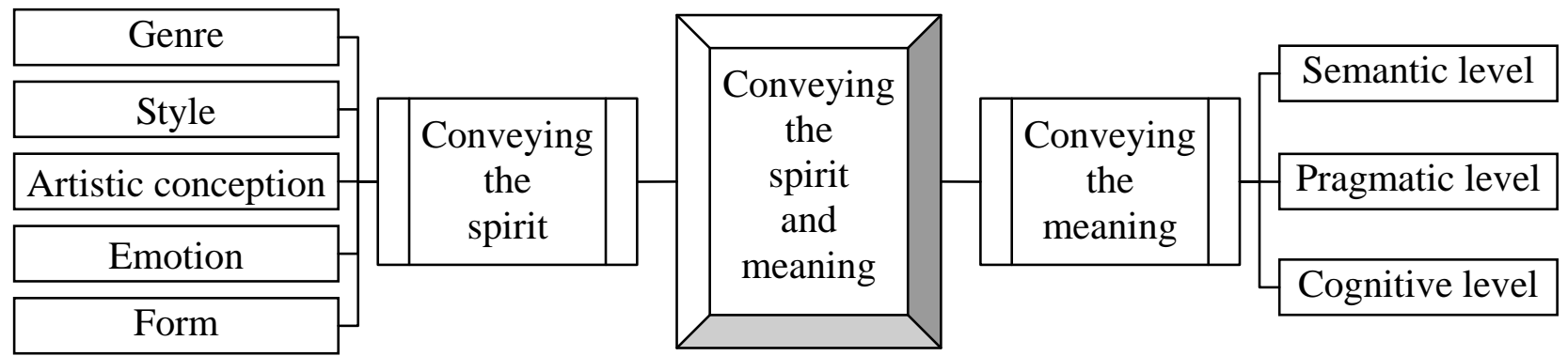

Fig. 1. Main points of "conveying the spirit and meaning"

"Conveying the spirit and meaning" inherited the traditional Chinese translation theory of thought pattern, starting from the noumenon of translation to explore the translation principles and standards, with distinct Chinese characteristics, which belongs to the category of Chinese traditional translation theories, the weakness is lack of systematic theory, and therefore not to the formation of theory of growth. With the framework of western modern translation and philosophy as a frame of reference, the relevant issues of Chinese traditional translation theories are cleared up, and the related topics are sought out, and the theoretical interpretation, to be structured and clear, so as to form a dialogue with the international translation community. And foreign translation circle form dialogue, only from the perspective of translation is not enough, also need to organize and interpret, namely from the theory of "conveying the spirit and meaning" of a full range of "packaging" the form a unique English translation of Chinese classics theory, and integrate into the international translation theory to, fully embodies the traditional Chinese theory of translation ontology and practical.

\section{Inheritance and Development of "Faithfulness, Expressiveness and Elegance" Standard}

"Faithfulness, expressiveness and elegance" is put forward by China at the end of the Qing Dynasty new enlightenment thinker Yan Fu, talked about "translate introductory remarks" in Tianyan Lun that translation is "faithfulness, expressiveness and elegance". The translation theory of "faithfulness, expressiveness and elegance" has opened up a stage for the further study of modern translation theory. The "faithfulness" is the basis of translation. Translation of the original text of a kind of objective reporting, the translation process is objective reproduction of the original purpose, the translator is achieved without dyslexia middle must be faithful to the original, can not be made hard health code. In order to achieve the "faithfulness", the most important is that the translator should fully understand the original text and try to avoid the misunderstanding and Misreading of translation. Translation not only to make clear, but also to fully express the author's purpose, the full performance of the central. Translation can not blindly copy the original structure, when necessary, can make a big adjustment. The translator should have a certain understanding of western culture, not simply to be equated with western culture. Works Chinese cultural classics, not only aim high, and the language style is elegant, beautiful. "Elegant" means "beautiful, noble, not vulgar". In the process of the completion of the letter and reach the goal, as far as possible to pursue the beauty and elegance of the words [11]. The core content of "Faithfulness, expressiveness and elegance", as shown in Fig. 2.

The integration of the thought of "faithfulness, expressiveness and elegance" and the western 
translation theories. "Faithfulness" is the "good faith" relationship between the original text and the target text. "Keeping the contents of the original text" is the basic rule in translation practice. In the translation process, the translator should express the meaning of the original text as far as possible. One hundred percent of "good faith" is not achieved, the translator can sacrifice a part of "honesty", in order to achieve most of the content to achieve "good faith" of the target. The pursuit of "honesty" is the key to the exchange between the original text and the target text. Once you break the promise of the original text, the translation no matter how gorgeous words can not express the original idea. "Expressiveness" is a kind of thought, is the idea of the original text as well as the mood to use accurate words and expressions to express. In the process of translation, the translator should take into account the different languages, different cultures, different religions and customs, different ways of thinking and so on. This series of problems have caused the "non translation" in translation. The target of the translator is to translate the soul and essence of the original text as much as possible. "Elegance" is a kind of style of reproduction, is a kind of re creation of the original style as much as possible to reproduce the original style. The translator's "source of life" is in the original. On the basis of the author's intention of following the original author, the translator's subjective views and attitudes are permeated in the target language, and the greatest degree of the original artistic conception is excavated, which is the embodiment of translation art.

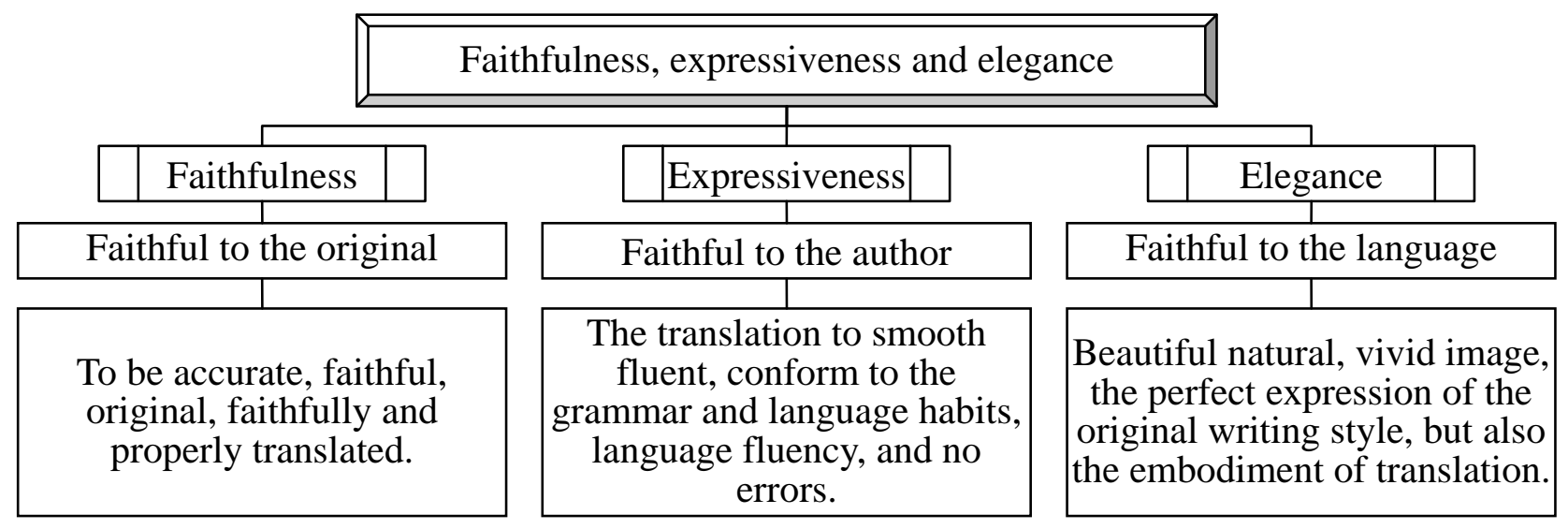

Fig. 2. Core content of "faithfulness, expressiveness and elegance"

The inheritance and development of "faithfulness, expressiveness and elegance". The translation theory of "faithfulness, expressiveness and elegance" has long been attached importance to the translation field, and has been developing and perfecting constantly. There are two reasons for this: first, the translation criteria of "faithfulness, expressiveness and elegance", the main features of the translation work, show the requirements of translation work. Translation is to pay attention to their words, faithful to the original, full of beauty. Other standard of translation is to enrich and improve. Second, "faithfulness, expressiveness and elegance" translation criteria, have inclusive, open and fusion of innovative character. After more than a century, the translation criteria of "faithfulness, expressiveness and elegance" of people's understanding and grasp of it is not limited to the original intention, but has a new understanding and interpretation. In the background of global culture, the relationship between eastern and Western culture is being updated. On the other hand, it is a new form of conflict. On the other hand, it goes to the dialogue and complementary. Various theories are communicated with each other, to foreign translation theory to good at the excavation and innovation of traditional Chinese translation theory, especially its "faithfulness, expressiveness and elegance" as the core of translation theory the constantly enriched and improved, and always maintain the vitality, which is the translation practice of translation theory innovation to expand the reaction and further demand. 


\section{Conclusion}

The translation of ancient books and records in English has ushered in a good development opportunity. With the deepening of reform and opening up, China's economic, political, and cultural parties have made considerable progress, the Chinese nation is rising, the world's influence continues to expand. At the same time, the people of the world know that China is becoming more and more powerful, and the cultural exchanges between China and foreign countries are becoming more and more active. Chinese culture is to go abroad, to the world with unprecedented scale, breadth and depth. The development of Chinese classics translation of the cause of the world to understand China's long and splendid history and culture to build a bridge of communication. How the classical translation into translation of classical, classical consciousness and material to lofty aspirations, selected books in fine. The second is should be based on the translation in the target culture, and respect the target language. The three is to be meticulous, with a tireless, hard study of academic spirit. Through the research of this paper, the present situation and achievements of the research on English translation of Chinese cultural classics are mastered.

\section{Acknowledgement}

This work is supported by social science fund project of Liaoning province (L15BWW004): Improving the Strategy of English Translation Level for Chinese Cultural Classics.

\section{References}

[1] X. Y. Zhao, "An Investigation into the English Translation of Chinese Classics," Journal of Hubei University of Education, vol. 29, no. 9, pp. 115-118, 2012.

[2] F. Xu, "The Usefulness of Eco - translatology for Translating Chinese Classics: a Case Study of Arthur Willy's Translation of Daodejing," Master's degree of Beijing Foreign Studies University, 2014.

[3] C. J. Zhao, Y. C. Liu, "The present situation, problems and future perspectives of translation and research of Chinese Classics," Journal of Yanshan University (Philosophy and Social Sciences Edition), vol. 15, no. 4, pp. 60-65, 2014.

[4] Y. Sun, Z. S. Li, "The Direction and Trend of the Development of Classics Translation: Take the 8th national conference on classics translation for example," Journal of Yanshan University (Philosophy and Social Sciences Edition), vol. 15, no. 2, pp. 95-98, 2014.

[5] Z. X. Huang, "English translation of Chinese Classics: opportunities and challenges," Social Sciences in Ningxia, vol. 27, no. 6, pp. 177-179, 2008.

[6] H. Y. Wang, "Problems of Translating Chinese Classics and Solutions," Chinese Culture Research, vol. 23, no. 2, pp. 59-68, 2015.

[7] R. L. Li, "Differentiate and analyse on translation criterion for 'conveying the spirit and meaning' of Wang Rongpei," Journal of Tianjin Foreign Studies University, vol. 19, no. 3, pp. 32-36, 2012.

[8] Y. He, "Translation thought of 'conveying the spirit and meaning': Take English translation 'Drink' (fifth) of Wang Rongpei as an example," Journal of Chifeng University (Philosophy and Social Science Chinese Edition), vol. 35, no. 6, pp. 212-214, 2014.

[9] J. C. Hao, "Explore and analyse on translation theory for 'conveying the spirit and meaning'," Journal of Tibet Nationalities Institute (Philosophy and Social Sciences Edition), vol. 33, no. 3, pp. 128-132, 2012.

[10] Y. Y. Fu, "'Conveying the Meaning in its Full Flavor': Towards the Construction of the Theoretical System of Translating Chinese Classics into English," Doctor's degree of Soochow University, 2011. 
[11] R. S. Na, "Translation thought and western translation Road on 'Faithfulness, Expressiveness and Elegance' of Yanfu," Lantai World, vol. 28, no. 34, pp. 51-52, 2013.

[12] F. R. Li, "Contrastive Analysis on 'Faithfulness, Expressiveness and Elegance' and Western Translation Theories," Journal of Changchun Normal University, vol. 33, no. 6, pp. 96-97 2014. 